\title{
Potential Monoclonal Antibody Therapy for the Treatment of Ovarian Cancer
}

\author{
Gregory Lee, Mingang Zhu and Bixia Ge \\ UBC Center for Reproductive Health, \\ The University of British Columbia Vancouver
}

Canada

\section{Introduction}

Although ovarian cancer is the fifth most common cancer among women, it causes more death than any other type of female reproductive cancer (Mørch et al., 2009). Besides difficulties in early detection, limited options for the treatment of ovarian cancer at late stages have been the major cause of high mortality rate (Jemal et al., 2003). About $76 \%$ of women with ovarian cancer survive 1 year after diagnosis, but only about $45 \%$ will live 5 years after diagnosis (Choi et al., 2008). Therefore, it may be desirable to look for alternative means of treating this type of cancer rather than the conventional ones including chemo- or radiotherapy.

During the last two decades, target-oriented antibody-based anti-cancer drugs have become the main stream choices for cancer treatments in humans. Although the efficacy of cancer treatments varies greatly with individual cases, overall improvements of patients' care and survival are significant, when compared to those of the conventional ones. Besides those approved by the FDA of the United States of America for the clinical treatments of cancer, numerous antibody-drug candidates are still at various stages of clinical trials and pending for the final approval by the FDA (Waldmann, 2003).

Generally speaking, the majority of antibody-based anti-cancer drugs are target-oriented and the adverse side effects upon infusion of the antibody drugs are relatively mild as compared to those of the traditional ones. Therefore, selections of suitable targets against the tumor cells have become an essential step for the long term antibody drug development. In general, the ideal tumor target for the antibody drugs can be selected based on its accessibility, high abundance and surface homogeneity. Moreover, it should not be highly expressed on normal cells or tissues, especially the vital organs in humans (McGuire et al., 1996).

Recently, two monoclonal antibodies were identified and selected based on these criteria for ovarian cancer. One is RP215 which recognizes a carbohydrate-associated epitope found preferentially in cancer cell-expressed immunoglobulin superfamily proteins, designated in general as CA215. The other is GHR106 which was shown to react with the extracellular domain of human GnRH receptor. Both CA215 and GnRH receptor are widely expressed among cancer cells of different tissue origins, especially those of the human ovary with positive rates ranging from $60-80 \%$ (Lee et al., 2008, 2009; Lee \& Ge, 
2010a). The binding of either of these two monoclonal antibodies was found to inhibit the growth of ovarian cancer cells in vitro and in vivo through studies of induced apoptosis and complement-dependent cytotoxicity. Therefore, additional preclinical studies were performed to elucidate the mechanisms of action of these monoclonal antibodies as anticancer drugs for the treatment of ovarian cancer. These studies should represent our efforts to demonstrate the potential use of these monoclonal antibodies as the anti-ovarian cancer drugs in the future.

\section{Results and discussion}

In this study, two monoclonal antibodies, RP215 and GHR106, were evaluated to see if they are suitable drug candidates for the potential treatment of ovarian cancer. Several in vitro and in vivo experiments were performed including (1) immunohistochemical staining and Western blot assay to reveal the relative abundance of target antigens, CA215 and GnRH receptor, respectively, each of which appears on the surface of cancer cells of the ovary, (2) apoptosis and complement-dependent cytotoxicity assays to demonstrate the respective anti-cancer efficacy of these two monoclonal antibodies, (3) elucidation of respective molecular mechanisms of action of RP215 and GHR106 as anti-cancer drugs through gene expression/regulation studies, (4) nude mouse experiments to reveal the dose-dependent inhibition of the growth of tumor cells and (5) construction of chimeric forms of RP215 and GHR106 monoclonal antibodies for future preclinical and clinical studies, (6) clinical evaluations of CA215 levels from serum specimens of cancer patients by using the established enzyme immunoassay kits, and (7) glycoanalysis to elucidate the proposed structure of carbohydrate-associated epitope(s) recognized by RP215 in CA215.

\subsection{Immunohistochemical studies and Western blot assay}

RP215 and GHR106 monoclonal antibodies were found to react with antigens localized on the surface of a variety of cancer cells including that of the ovary. By indirect immunohistochemical studies, it can be shown that three of the selected ovarian cancer cell lines, including OC-3-VGH, OVCAR-3, and SKOV-3, were strongly stained with RP215 and GHR106, respectively, whereas normal mouse IgG as the negative control gave little or no colour staining. The results of such an analysis are presented in Figure 1A (Lee et al., 1992, 2008, 2009; Lee \& Ge, 2010a). The immunohistochemical studies of selected cancerous tissue sections of the human ovary were also performed with RP215 as the primary antibody probe. The results are presented in Figure 1B for comparisons. In a separate study, GHR106 was used as a probe to carry out immunohistochemical staining of cancerous tissue sections of the ovary from patients at four various stages of ovarian cancer (Chien et al., 2004). From the results of this analysis, it was generally concluded that the positive staining rates of ovarian cancer tissue sections increase with the stages of this disease $(37.5 \%$ at stage I to $100 \%$ at stage IV) (Chien et al., 2004). In contrast, the immunohistochemical staining of tissue sections of the normal ovary showed negative staining results. The results of such analysis are summarized in Figure 1C.

The antigens recognized by RP215 and GHR106 in the cell extract of ovarian cancer cells were also determined by Western blot assay (Lee et al., 2008, 2009; Lee \& Ge, 2010a). In the case of RP215, the corresponding antigen, CA215, was found to have a molecular size ranging from 50 to $75 \mathrm{kDa}$ for the cell extract from either of the three ovarian cancer cell 
lines (OC-3-VGH, OVCAR-3 and SKOV-3). When GHR106 was used as the probe for the same assay, the molecular weight of GnRH receptor of these cancer cells was found to be 60 $\mathrm{kDa}$. The results were consistent with those reported previously for human GnRH receptor (Lee \& Ge, 2010a). The results of such analysis are presented in Figure 2.

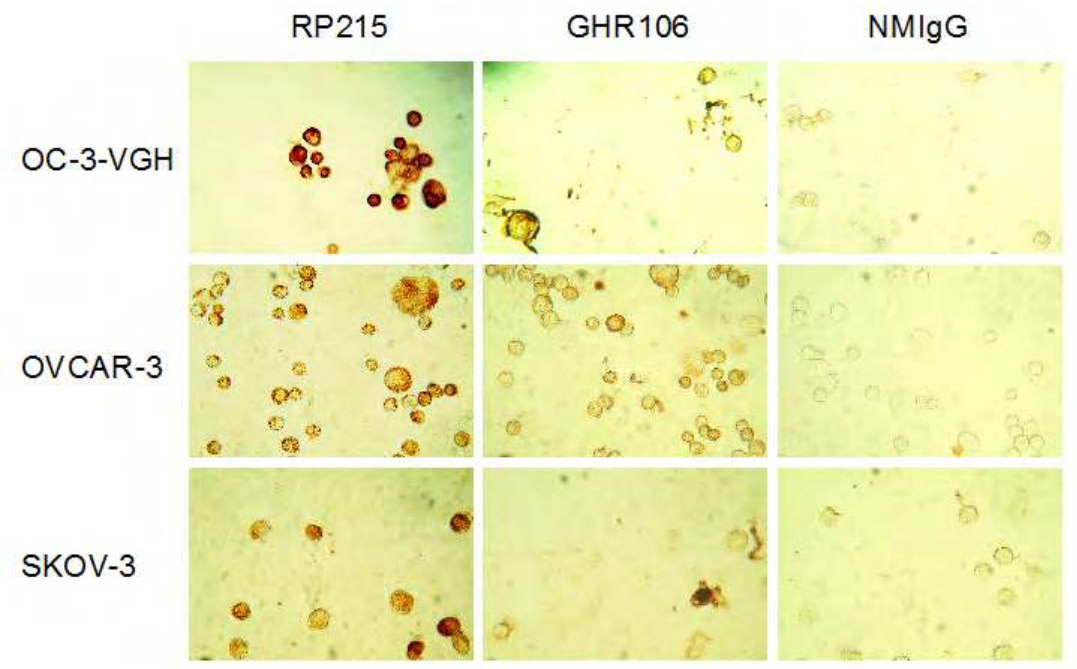

(A)

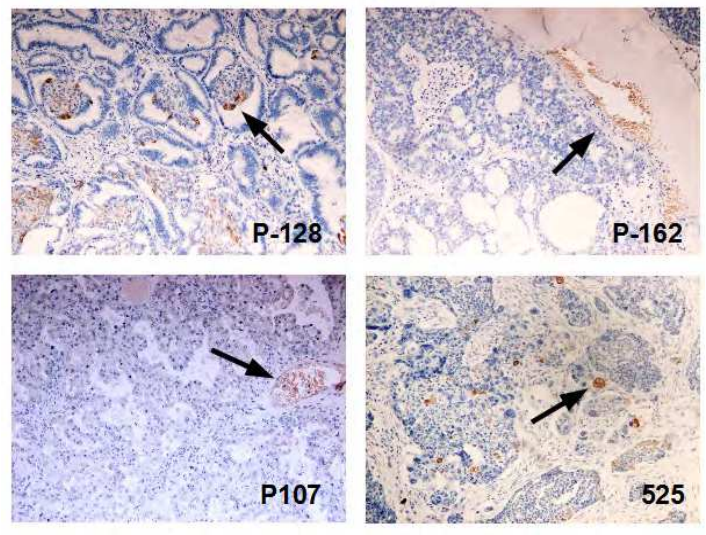

(B)

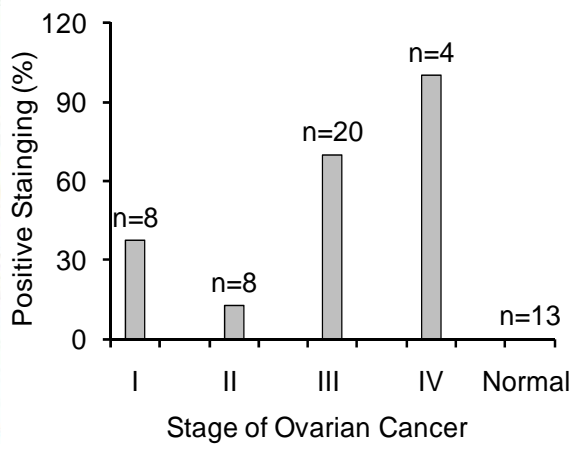

(C)

Fig. 1. (A) Immunohistochemical study to reveal staining of three different ovarian cancer cell lines, OC-3-VGH, OVCAR-3 and SKOV-3 with RP215, GHR106 and normal mouse IgG (NMIgG, negative control); (B) Immunohistochemical study to reveal staining of selected ovarian cancer tissue sections (P-128, P-162, P107 and 525) with RP215. The areas of staining are highlighted with the arrows; (C) Results of immunohistochemical staining of GnRH receptor of ovarian tissue sections at different stages (I to IV) of ovarian cancer. $n=$ total number of specimens. 


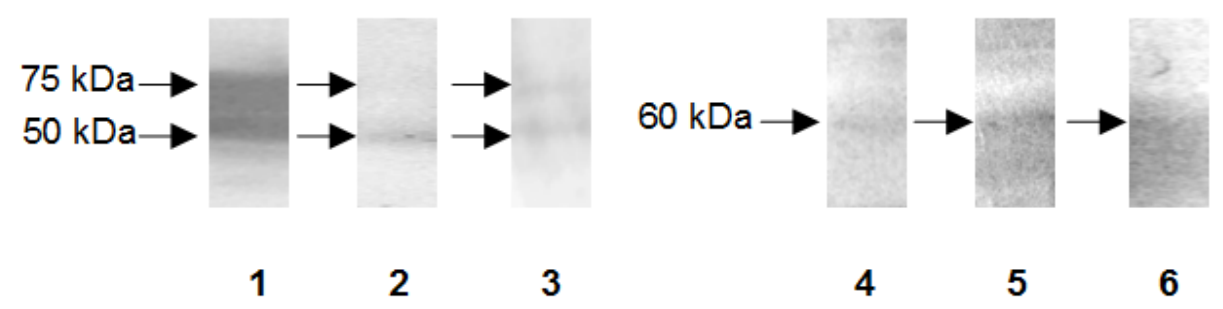

Fig. 2. Western blot assay to reveal protein bands from the extract of three ovarian cancer cell lines, OC-3-VGH (1 and 4), SKOV-3 (2 and 5) and OVCAR-3 (3 and 6), respectively, when probed with RP215 (lanes 1, 2 and 3) as well as GHR106 (lanes 4, 5 and 6). The molecular weight markers of $50 \mathrm{kDa}, 60 \mathrm{kDa}$ and $75 \mathrm{kDa}$ are indicated by arrows.

\subsection{Effects of RP215 and GHR106 monoclonal antibodies on the induction of apoptosis to ovarian cancer cells}

By using terminal deoxynucleotidyl transferase dUTP nick end labelling (TUNEL) assay, the induced apoptosis of cancer cells upon incubation with RP215 and GHR106 could be clearly demonstrated. As shown in Figure 3A, all of the three ovarian cancer cell lines were found to undergo significant cellular apoptosis, when incubated with $10 \mu \mathrm{g} / \mathrm{mL}$ of either RP215 or GHR106 (24 - $48 \mathrm{~h})$. A significant apoptosis of cancer cells was also induced upon treatments with $0.1 \mu \mathrm{g} / \mathrm{mL}$ of a GnRH antagonist, Antide or GnRH. Under the same assay conditions, the chimeric form of RP215, ChRP215, was found to induce apoptosis of the OC-3-VGH cancer cell line, similar to that observed for murine RP215. The results of such a comparative analysis are also summarized in Figure 3B. Similarly, chimeric form of GHR106, ChGHR106, was found to have the same effects as that of GHR106 in inducing apoptosis of the ovarian cancer cells (Figure 3B).

In addition to RP215, the induction of apoptosis to OC-3-VGH ovarian cancer cell has also been confirmed with other RP215-related monoclonal antibodies (RCA10, RCA100, RCA104, RCA110 and RCA111, see section 2.11), as demonstrated in Figure 3C.

\subsection{Effects of RP215 and GHR106 monoclonal antibodies on complement-dependent cytotoxicity of ovarian cancer cells}

The complement-dependent cytotoxicity assay was also employed to study the induction of complement-dependent cell lysis to OC-3-VGH ovarian cancer cells in the presence of complement and RP215 or GHR106 (10 $\mathrm{gg} / \mathrm{mL}$ for $2 \mathrm{~h}$ incubation). The chimeric forms of monoclonal antibodies, ChRP215 or ChGHR106, also demonstrated a similar degree of complement-dependent cytotoxicity reaction to cultured ovarian cancer cells under the same conditions of incubation. In contrast, complement alone or complement with GnRH antagonist, Antide $(0.1 \mu \mathrm{g} / \mathrm{mL})$, revealed no effect on complement-dependent cytotoxicity to ovarian cancer cells (data not shown). Results of this complement-dependent cytotoxicity assay with different monoclonal antibodies plus complement are summarized in Figure 4 for comparisons. 

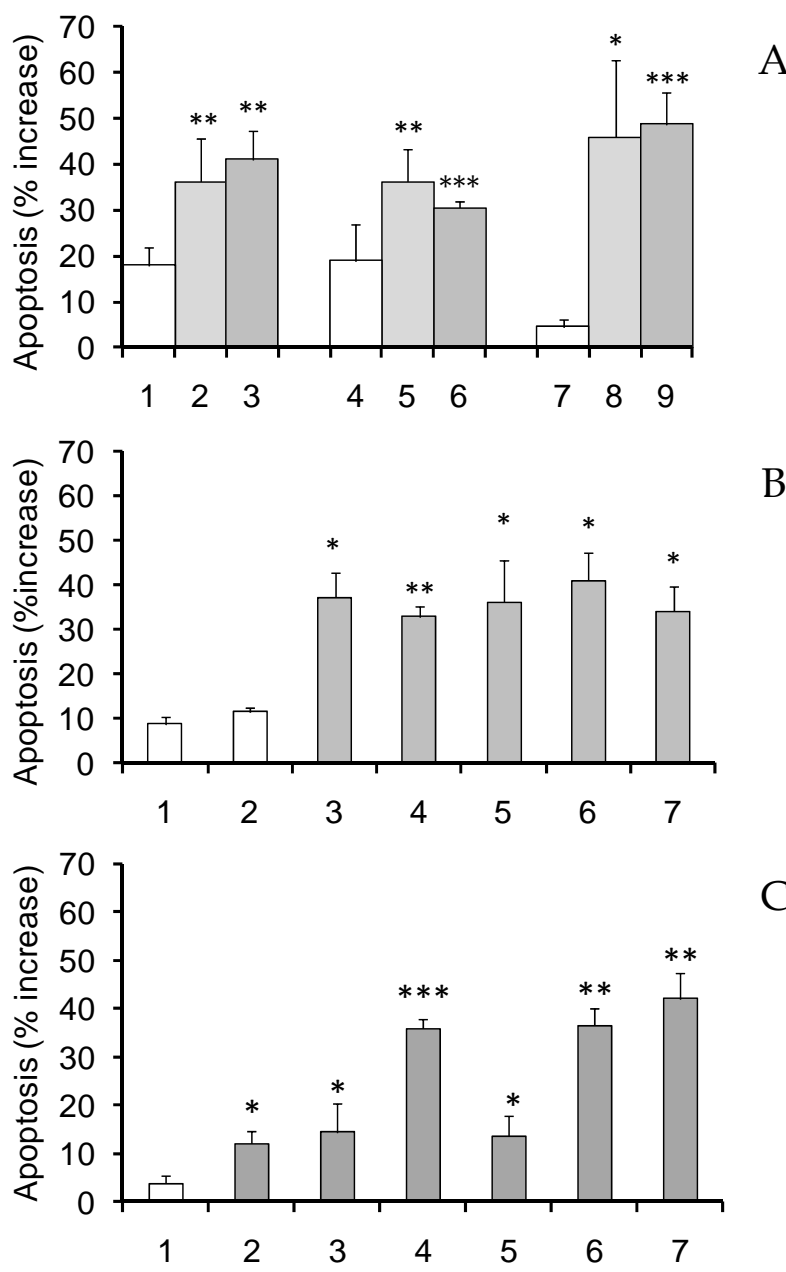

Fig. 3. (A) The TUNEL assay to demonstrate the increase in apoptosis of cancer cells in response to the treatment of cultured OC-3-VGH (Lanes 1-3), OVCAR-3 (Lanes 4-6) and SKOV-3 (Lanes 7-9) cells for $48 \mathrm{~h}$ with either of the following monoclonal antibodies (dose: $10 \mu \mathrm{g} / \mathrm{mL}$ each): normal mouse IgG (Lanes 1, 4, 7), RP215 (Lanes 2, 5, 8) and GHR106 (Lanes $3,6,9$ ), respectively; (B) The TUNEL assay to demonstrate the increase in apoptosis of OC-3VGH cells in response to the treatment by chimeric as well as murine monoclonal antibodies (dose: $10 \mu \mathrm{g} / \mathrm{mL}$ each) for $48 \mathrm{~h}$ : Lane 1: non treatment; Lane 2: normal mouse IgG; Lane 3: ChRP215; Lane 4: ChGHR106; Lane 5: RP215; Lane 6: GHR106; and Lane 7: $0.1 \mu \mathrm{g} / \mathrm{mL}$ Antide; (C) The TUNEL assay to demonstrate the increase in apoptosis of cancer cells in response to the incubation of OC-3-VGH cancer cells for $48 \mathrm{~h}$ with the following antibodies $(1 \mathrm{\mu g} / \mathrm{mL}$ each): Lanes 1-7 correspond to that of normal mouse IgG, RCA10, RCA100, RCA104, RCA110, RCA111, and RP215, respectively (to be described in section 2.11). All data presented are statistically significant at ${ }^{*} \mathrm{P}<0.05$, ${ }^{* *} \mathrm{P}<0.01$, and ${ }^{* * *} \mathrm{P}<0.001$. 


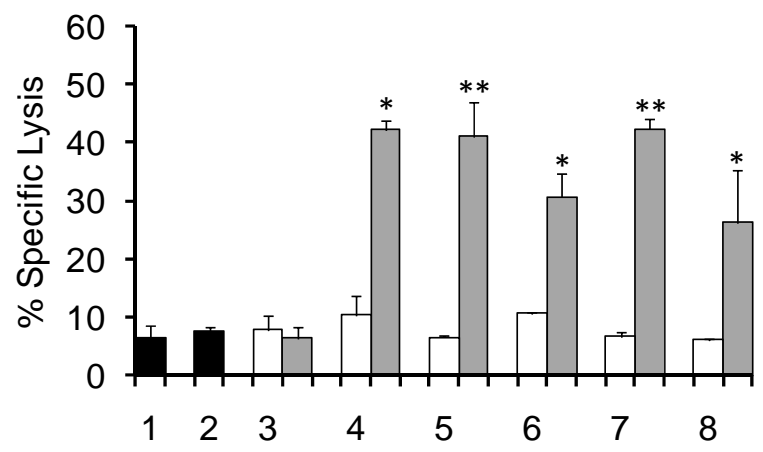

Fig. 4. Complement-dependent cytotoxicity assay to demonstrate the respective effects of normal mouse IgG (Lane 3), ChRP215 (Lane 4), ChGHR106 (Lane 5), RP215 (Lane 6), GHR106 (Lane 7), and goat anti-human IgG (Lane 8) on the complement-dependent lysis of OC-3-VGH ovarian cells. White, monoclonal antibody $(10 \mu \mathrm{g} / \mathrm{mL})$ alone; Grey, monoclonal antibody $(10 \mu \mathrm{g} / \mathrm{ml})$ plus complement; Black, non-treatment (Lane 1) or $3 \mu \mathrm{L}$ freshly prepared rabbit baby complement (Lane 2 ) as control. * and ${ }^{* *}$ indicate statistical significance of $\mathrm{P}<0.05$ and $\mathrm{P}<0.01$, respectively.

\subsection{Effects of RP215 or GHR106 monoclonal antibodies on the expression of selected genes in ovarian cancer cells}

Molecular mechanisms of action by which RP215 or GHR106 inhibit the growth of OC-3VGH ovarian cancer cells were elucidated through the studies of gene regulation by qualitative and semi-quantitative RT-PCR (Lee \& Ge, 2010a; Kang et al., 2003; Leung et al., 2003; Gründker et.al., 2000). A number of genes related to the growth of cancer cells were examined for their expressions in response to the treatment of cultured ovarian cancer cells with either of these two monoclonal antibodies for $48 \mathrm{~h}$. The results of this qualitative analysis with a number of selected genes are summarized in Table 1.

Parallel to this gene expression study, the effects of GnRH antagonist, Antide, on the expression of selected genes in ovarian cancer cells are also presented for comparisons with those of GHR106. Based on the results of this comparative analysis, it was clearly demonstrated that both GHR106 and Antide induce the same patterns of gene regulations to ovarian cancer cells upon their respective ligand binding.

Generally speaking, the incubation of RP215 with OC-3-VGH ovarian cancer cells was found to increase the gene expression of IgG and NFKB1 (Li \& Verma, 2002), but genes of ribosomal proteins, P0, P1 and P2 were significantly down-regulated (Lee \& Ge, 2010b). RP215 incubation to cultured cancer cells were found to have no effect on EGF (epidermal growth factor) (Gründker et al., 2000), but caused a significant decrease in the gene expression of $c$-fos (Dragunow \& Faull, 1989). On the other hand, under the same incubation conditions, both GHR106 monoclonal antibody and GnRH antagonist, Antide, were shown to up-regulate the expression of GnRH gene, but not that of GnRH receptor (Lee \& Ge, $2010 b)$. Gene regulations of ribosomal proteins by GHR106 or Antide were also different from those by RP215. While P0 gene was found to be down-regulated, P1 gene was upregulated instead (Lee \& Ge, 2010b). Although no changes in $c$-fos gene regulation were observed, EGF was found to be down-regulated significantly with the treatment of GHR106 or Antide. The results of such a comprehensive analysis with OC-3-VGH ovarian cancer 
cells are presented in Table 1. From this gene regulation analysis, it can be shown that the molecular mechanisms of action by which the apoptosis of cancer cells is induced with RP215 are quite different from those of GHR106 or GnRH antagonists, Antide.

\begin{tabular}{|c|c|c|c|}
\hline Gene & RP215 $(10 \mu \mathrm{g} / \mathrm{ml})$ & GHR106 $(10 \mu \mathrm{g} / \mathrm{ml})$ & Antide $(0.1 \mu \mathrm{g} / \mathrm{ml})$ \\
\hline $\mathrm{GnRH}$ & $\mathrm{N} \cdot \mathrm{T}^{\mathrm{a}}$ & $\uparrow$ & $\uparrow$ \\
\hline GnRH receptor & N.T & N.C & N.C \\
\hline $\lg G$ & $\overline{\uparrow^{c}}$ & N.T & N.T \\
\hline $\mathrm{NFKB} 1^{\mathrm{b}}$ & $\uparrow$ & N.T & N.T \\
\hline P0 & $\downarrow^{c}$ & $\downarrow$ & $\downarrow$ \\
\hline P1 & $\downarrow$ & $\uparrow$ & $\uparrow$ \\
\hline $\mathrm{P} 2$ & $\downarrow$ & N.C & N.C \\
\hline EGF & N.C ${ }^{a}$ & $\downarrow$ & $\downarrow$ \\
\hline c-fos & $\downarrow$ & N.C & N.C \\
\hline
\end{tabular}

${ }^{a}$ N.T: not tested; N.C: not changed

bAbbrevations used: NFKB1: nuclear factor of kappa light polypeptide gene enhancer in B cells 1; P0, P1 and P2 are genes expressed by selected ribosomal proteins; c-fos: cellular oncogene proteins; EGF: epidermal growth factor.

c $\uparrow$ and $\downarrow$ indicate significant up and down gene regulations, respectively when compared to that of GAPDH (Glyceraldehyde 3-phosphate dehydrogenase).

Table 1. Gene regulation studies in cultured OC-3-VGH ovarian cancer cells using RP215, GHR106 and Antide.

\subsection{Expressions of immunoglobulins of different classes from ovarian cancer cells derived from a single clone}

OC-3-VGH ovarian cancer cells which were derived from a single clone were found to express IgG, IgA and IgM, simultaneously. This is in contrast with those of B cells, each of which expresses only a single class of immunoglobulins. (Qiu et.al., 2003; Huang et al.,2008; Zhang et al., 2010 ). This observation strongly suggests that immunoglobulins may be expressed by cancer cells through different mechanisms as compared to those of normal human B cells (Zheng et al., 2009).

\subsection{Nude mouse experiments}

Our previous studies have demonstrated that CA215 and GHR106 receptor are expressed on the surface of many human cancer cells including those of the ovary. Through in vitro studies with induced apoptosis and complement-dependent cytotoxicity reactions, it was clearly demonstrated that CA215 and GnRH receptor on the surface of cancer cells may be suitable targets by the respective monoclonal antibodies (Lee et al., 2009; Lee \& Ge, 2010a). Therefore, nude mouse experiments were performed with OC-3-VGH ovarian cancer cell line as the model to evaluate the anti-tumor efficacy of RP215 monoclonal antibody.

Following a single injection of three different doses of RP215 (1-10 mg/kg doses) at the time of tumor implantation, a significant inhibition of tumor growth was observed in a dose dependent manner. Fifteen days after the tumor implant and antibody treatments, the tumor volumes were compared. As shown in the histogram of Figure 5, the dose-dependent inhibition of tumor growth by RP215 was statistically significant as compared to that of the 
negative control. In addition, I131-labelled RP215 $(12 \mu \mathrm{Ci} / \mathrm{mg})$ was found to be more effective in the suppression of tumor growth than the unlabelled antibody.

Several nude mouse experiments were also performed with models of several other cancer cell lines. These included: C33A (cervix) and SK-MES-1 (lung) for RP215 as well as Hep2G (liver) for GHR106. In each case, significant tumor reduction or inhibition of tumor growth was observed 14-17 days after tumor implantation and subsequent injection of antibody drugs (RP215 or GHR106: dose $10 \mathrm{mg} / \mathrm{kg}$ ) according to similar protocols for nude mouse experiments as described above (data not presented).

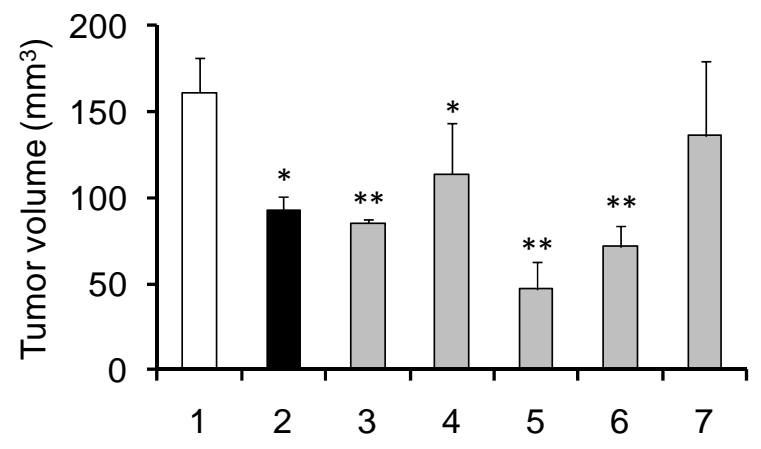

Fig. 5. Tumor volumes at Day 15 were compared for nude mice treated by RP215 in unlabelled and I131-labelled form (specific activity $12 \mu \mathrm{Ci} / \mathrm{mg}$ ): Lane 1: negative control (no treatment, open column); Lane 2: positive control (black column, $60 \mathrm{mg} / \mathrm{kg}$ cyclophosphamide ); Lane 3: AH (antibody high dose: $10 \mathrm{mg} / \mathrm{kg}$ ); Lane 4: AM (antibody medium dose: $5 \mathrm{mg} / \mathrm{kg}$ ); Lane 5: I-AH (I131-labeled antibody high dose: $10 \mathrm{mg} / \mathrm{kg}$ ); Lane 6: I-AM (I131-labeled antibody median dose: $5 \mathrm{mg} / \mathrm{kg}$ ); Lane 7: I-AL (I131-labeled antibody low dose: $2 \mathrm{mg} / \mathrm{kg})$. Data are statistically significant at ${ }^{*} \mathrm{P}<0.05,{ }^{* *} \mathrm{P}<0.01$.

\subsection{Anti-idiotypic monoclonal antibodies as anti-cancer vaccines}

RP215 monoclonal antibody was shown to recognize carbohydrate-associated epitope which is preferentially expressed in a mixture of different glycoproteins designated as CA215 identified in many cancer cells in humans. Polyclonal and rat monoclonal antibodies against the Fab-idiotypic domains of RP215 were generated and characterized (Lee et al., 2010a and 2010b; Lee \& Ge, 2010a and 2010b). The anti-idiotypic (aid) antibodies were found to bear the internal images of the RP215-specific carbohydrate-associated epitope. Following immunizations in mice with rat anti-idiotypic monoclonal antibody, the resulting anti-aid or Ab3 sera were found to behave like RP215 in biochemical and immunological properties (Lee et al., 2010a and 2010b; Lee \& Ge, 2010a and 2010b).

By Western blot assay, Ab3 antisera were found to react with protein bands identical to those recognized by RP215. By immunohistochemical staining study, the majority of cancer cells from different tissue origins were positively stained by both Ab3 antisera and RP215. Ab3 antisera were shown to induce apoptosis, similar to that observed for RP215. Based on these experimental observations, it was therefore hypothesized that rat anti-idiotypic monoclonal antibodies or its Fab fragments bear the internal images of RP215-specific epitope (Lee et al., 2010a and 2010b; Lee \& Ge, 2010a and 2010b) and may be suitable as anti-cancer vaccines to induce Ab3 responses in humans for cancer treatments or preventions (Lee et al., 2010b). 


\subsection{Molecular identity of CA215 and expression of immunoglobulin superfamily proteins by cancer cells}

RP215 monoclonal antibody was shown to react with carbohydrate-associated epitope preferentially expressed by cancer cells in a mixture of glycoproteins designated as CA215. To reveal the molecular identity of CA215, MALDI-TOF MS (matrix assisted laser desorption ionization time-of-flight mass spectrometry) analysis was performed for more than one hundred tryptic peptides of CA215 affinity-purified from the shed medium of cultured OC-3-VGH ovarian cancer cells. It was generally concluded that CA215 consists mainly of immunoglobulin superfamily proteins (61\%) including immunoglobulins (42\%), T cell receptors (6\%) and cell adhesion molecules $(8 \%)$ as well as mucins $(7 \%)$ and other unrelated ones. Results of this analysis are summarized in Table 2.

\begin{tabular}{lc}
\hline \multicolumn{1}{c}{ Molecular Function/Category } & $\begin{array}{c}\text { Number of Peptides Matched } \\
\text { Total = 124 (Percentage) }\end{array}$ \\
\hline I. Antigen receptors & $52(42.0 \%)$ \\
Antibodies and immunoglobulins & $7(5.7 \%)$ \\
T cell receptor chains & $6(4.9 \%)$ \\
\hline II. Antigen presenting molecules & $10(8.1 \%)$ \\
MHC I and MHC II & $8(6.5 \%)$ \\
\hline III. Adhesion molecules & $7(5.7 \%)$ \\
\hline IV.Cytokine and growth factors & $12(9.7 \%)$ \\
\hline V. Receptor tyrosine kinase/phosphatise & Total with homology ${ }^{\mathrm{a}}: 75 / 124(60.5 \%)$ \\
\hline VI. Others & $9(7.3 \%)$ \\
\hline Immunoglobulin superfamily related (e.g. titin) &
\end{tabular}

a Excluding overlapping matched peptides

Table 2. MALDI-TOF MS analysis of tryptic peptides derived from affinity-purified CA215.

By using semi-quantitative RT-PCR of the cell extract of over 20 cancer cell lines, it was observed that as many as $80 \%$ of these cancer cells express T cell receptors ( $\alpha$ and $\beta$ chains) at significantly high levels including OC-3-VGH, OVCAR-3 and SKOV-3 cell lines. Results of such an analysis are summarized in Table 3. In contrast with the exception of Raji (lymphoma) and Jurkat ( $\mathrm{T}$ cell leukemia) cell lines, none of these cancer cell lines express CD3, CD4 and CD8 co-receptors and/or co-stimulator genes, indicating the non-functional nature of most of the cancer cell-expressed $T$ cell receptors. In addition, numerous immunoglobulin superfamily protein-like cell adhesion molecules such as CD47, CD54, CD58 and CD147 are also highly expressed among all the cancer cell lines. Widespread T cell receptor expressions among cancer cells may have implications on cancer immunotherapy via $\mathrm{T}$ cell activation as well as the induced tolerance of $\mathrm{T}$ cells caused by tumor-associated antigens in humans (Lee et al., 2011a). 


\begin{tabular}{c|cccc|c|c}
\hline Origin & \multicolumn{3}{|c|}{ Human Ovarian } & Lymphoma & $\begin{array}{c}\text { T-cell } \\
\text { leukemia }\end{array}$ \\
\hline Designation cell line & SKOV-3 & OVCAR-3 & OC-3-VGH & Raji & Jurkat \\
\hline ATCC NO. & HTB-77 & & & CCL-86 & TIB-152 \\
\hline TCR $(\alpha)^{\text {a }}$ & +++ & + & ++ & +++ & +++ \\
TCR $(\beta)$ & + & \pm & + & +++ & +++ \\
IgG (Fc) & + & ++ & + & ++ & + \\
CD3 & - & - & - & + & + \\
CD4 & - & - & - & - & - \\
CD8 & - & - & - & - & - \\
CD47 & ++ & ++ & ++ & ++ & ++ \\
CD54 & ++ & ++ & + & + & ++ \\
CD58 & ++ & ++ & ++ & ++ & ++ \\
CD147 & ++ & ++ & ++ & ++ & ++ \\
\hline
\end{tabular}

a Abbreviations used: TCR, T cell receptor ( $\alpha$ chain or $\beta$ chain)

bSignal intensities follow the order of +++ (strongest),,,,+++ \pm- (neg), GAPDH was used as the internal standards.

Table 3. Gene expressions of immunoglobulin superfamily proteins by RT-PCR.

\subsection{Structural elucidations of carbohydrate-associated epitope recognized by RP215 monoclonal antibody}

In collaboration with Complex Carbohydrate Research Center at University of Georgia, efforts have been made to elucidate the carbohydrate-associated epitope(s) recognized by RP215 in CA215. (Lee \& Ge, 2009). By using CA215 affinity-purified from OC-3-VGH ovarian and C33A cervical cancer cell lines, profiles of N-linked and O-linked glycans were analyzed and compared with those of other known glycoproteins from normal and cancerous tissues. In the case of N-linked glycans, high mannose and complex bisecting structures with terminal N-glycolylneuraminic acid were detected in CA215. In the case of O-linked glycans, several oligosaccharides were detected in CA215 with structures similar to those of mucins, but with terminal N-glycolylneuraminic acid. N-linked and O-linked glycosylation site mappings of CA215 were performed. A total of two N-linked and eight Olinked glycopeptides were detected. Protein BLAST search of peptide sequence homology revealed that two $\mathrm{N}$-linked and six O-linked glycopeptides were almost $100 \%$ matched to human immunoglobulin heavy chains. One of the remaining O-linked ones was matched to immunoglobulin superfamily proteins such as titin and hemicentin. Results of N-linked and O-linked glycosylation site mappings are summarized in Table 4. Based on the results of this extensive glyconanalysis, it can be suggested that both N-linked and O-linked glycans with unique terminal $\mathrm{N}$-glycolylneuraminic acid in CA215 are structurally related to those of mucins. However, N-glycolylneuraminic acid might not to be directly involved in the RP215 epitope recognition as no loss of CA215 activity was found when OC-3-VGH cells were cultured in medium containing human serum instead of fetal calf serum as culture medium supplement (Lee \& Azadi, 2011). 


\begin{tabular}{|c|c|c|}
\hline Accession Number & Peptide Detected ${ }^{a}$ & Peptide Sequence Homology of Proteins (\%) \\
\hline CAC12842.1 & EEQFNSTFR $^{\mathrm{a}}$ & Immunoglobulin heavy chain (Fc) $(100 \%)^{b}$ \\
\hline CAA04843.1 & EEQFNSTYR & Immunoglobulin heavy chain (Fc) (100\%) \\
\hline AAB60643.2 & LSVPTSEWQR & Cathepsin S (100\% \\
\hline AAK68690.1 & FTCLATNDAGDSSK & $\begin{array}{c}\text { Hemicentin (100\%) } \\
\text { Titin (100\%) } \\
\text { Palladin isoform } 4(92 \%) \\
\text { LRN4 (78\%) } \\
\text { Immunoglobulin superfamily proteins }\end{array}$ \\
\hline AAD38158.1 & DTLMISR & Immunoglobulin heavy chain (Fc) (100\%) \\
\hline AAC39746.2 & GYLPEPVTVTWNSGTLTNGVR & Immunoglobulin heavy chain (Fab) $(90 \%)^{\mathrm{c}}$ \\
\hline AAN76042.1 & SVSLTCMINGFYPSDISVEWEK & Immunoglobulin heavy chain (Fc) $(90 \%)$ \\
\hline CAJ75462.1 & QSSGLYSLSSVVSVTSSSQPVTCNV & Immunoglobulin heavy chain (Fab and Fc) (100\%) \\
\hline ABY48864.2 & VYTMGPPREELSSR & $\begin{array}{c}\text { Immunoglobulin heavy chain (Fc) (98\%) } \\
\operatorname{lgA} \text { variable region (89\%) } \\
\operatorname{lgM}(98 \%)\end{array}$ \\
\hline NP_001139647.1 & TFPSVR & $\begin{array}{c}\text { Zinc finger protein } 414 \text { isoform I (100\%) } \\
\text { Forkhead box protein C2 (100\%) } \\
\text { Immunoglobulin heavy chain variable region (83\%) }\end{array}$ \\
\hline
\end{tabular}

aBold letters indicate glycosylation sites bFc: constant region of immunoglobulins cFab: variable region of immunoglobulins

Table 4. Results of N-linked and O-linked glycosylation site mappings of CA215.

\subsection{Clinical diagnostic applications of RP215-based immunoassays}

RP215 was found to recognize carbohydrate-associated epitope(s) detected preferentially in the cancer cell-expressed CA215, but rarely found in normal cells. This monoclonal antibody alone can be used in sandwich immunoassays for the determination of soluble CA215, if multi-RP215-specific epitope exists in a given CA215 glycoprotein molecule. Therefore, serum levels of CA215 can be determined quantitatively by using RP215 for both capturing and signal detection in a typical sandwich enzyme immunoassay. This enzyme immunoassay has been used in the diagnostics and monitoring of ovarian cancer and cervical cancers (Lee, 2009). CA215 levels in serum specimens of cancer patients at different disease stages can be determined by this enzyme immunoassay kit. Typical results of this analysis from a group of ovarian cancer patients at different stages are presented in Figure 6. 


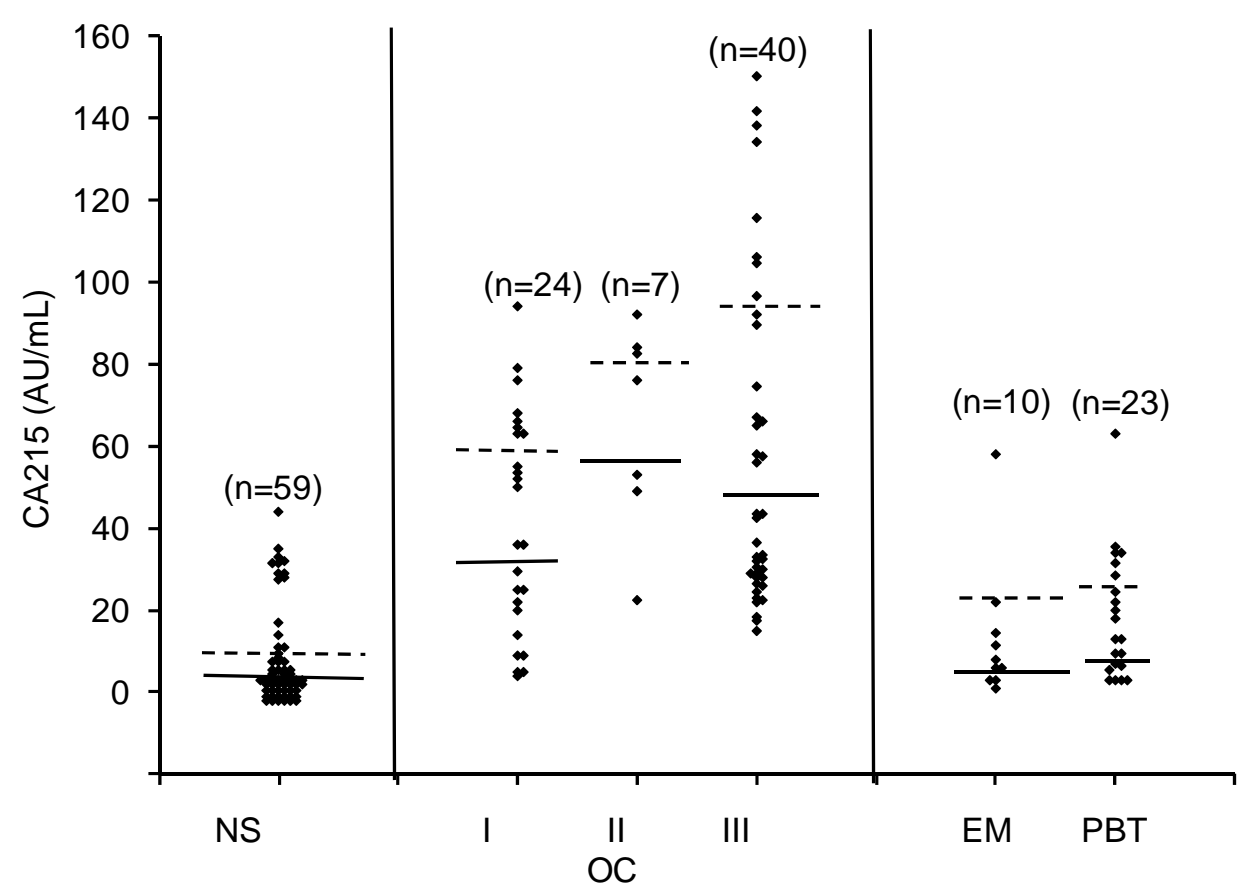

Fig. 6. Serum levels of CA215 pan cancer marker (expressed in AU/mL) for normal healthy individuals (NS) and for patients with ovarian cancer (OC) defined by respective stages (I, II, and III) of disease conditions and those with endometriosis (EM) and pelvic benign tumor (PET). Solid lines indicate the mean (M) serum CA215 levels in each category and dotted lines represent the mean values plus one standard deviation (SD). The number of cases in each category is indicated on the top of the scattered gram.

Statistics:

1. Normal control vs. ovarian carcinoma stage I ( $\mathrm{P}<0.001)$; stage II $(\mathrm{P}<0.001)$; stage III (P $<0.001)$; stage I vs. stage III $(\mathrm{P}<0.05)$; stage II vs. stage III $(\mathrm{P}>0.05)$.

2. Normal control vs. endometriosis $(\mathrm{P}>0.05)$.

3. Normal control vs. pelvic benign tumors $(\mathrm{P}=0.05)$.

Compared to the known biomarker for ovarian cancer, such as CA125, enzyme immunoassay for CA215 revealed a similar degree of sensitivity and specificity to those of the known biomarker, CA125. When both biomarkers are combined for clinical diagnosis, the detection sensitivity was found to increase significantly (from $68 \%$ to $87 \%$, $n=31$ ) (Lee, 2009). 
Serum CA215 levels were also found to be correlated with the conditions of clinical treatments. It is interesting to note that the mean serum CA215 levels remained at relatively high levels including those at pre-operative stages and within 7 days following surgical operations. In contrast, serum CA215 levels decreased significantly when determined 7 days after the surgical operations. (Lee, 2009).

By employing the same enzyme immunoassay kit, the clinical utility of CA215 as a pan cancer biomarker was evaluated with clinically defined serum specimens from over 500 cancer patients and compared with results obtained by nine other established cancer biomarkers including AFP, CEA, CA215, CA19-9, CA15-3, Cyfra21, etc. (Lee et al., 2010b). A combination of CA215 with other tissue-associated cancer markers generally resulted in much higher cancer detection rates. By Western blot assay with RP215, it was revealed that cancer cell-expressed IgG's with RP215-specific epitope were detected in patients' serum specimens which were shown to have high levels of CA215 by enzyme immunoassay. In contrast, normal human serum specimens revealed the absence of cancer cell-expressed CA215 as determined by the same enzyme immunoassay (Lee et al., 2010b).

In conclusion, RP215-based immunoassay kit may be suitable for the monitoring of cancer in patients including that of the ovary in terms of disease conditions as well as clinical treatments.

\subsection{Immunodominance of carbohydrate-associated epitope(s) recognized by RP215 in CA215}

During our investigation of the carbohydrate-associated epitope(s) recognized by RP215, it was observed that the immunodominance of this unique epitope(s) in CA215 exists in mice. When mice were immunized with affinity-purified CA215 derived from the shed medium of OC-3-VGH ovarian cancer cells, only five monoclonal antibodies (RCA10, RCA100, RCA104, RCA110 and RCA111) were recovered from about 1000 hybridomas generated by cell fusion between NS-1 myeloma cells and the spleen cells from mice immunized with purified CA215. Unexpectedly, all five were shown to react with carbohydrate-associated epitope(s) which were similar to that of RP215. Judging from comparisons of the primary structures of these five monoclonal antibodies and RP215, three distinct groups of monoclonal antibodies were categorized. Group I including RP215, RCA10 and RCA100 were shown to have identical amino acid sequences and react with the linear epitope of this unique carbohydrate-associated epitope. Group II (RCA104 and RCA111) and Group III (RCA110) monoclonal antibodies were found to recognize only the conformational structure(s) of this carbohydrate-associated epitope and lost their respective CA215 binding upon treatment with methanol or SDS. However, all the monoclonal antibodies were shown to exhibit common characteristics including (1) a decrease in CA215 binding upon the periodate treatment, (2) mutual pairing among monoclonal antibodies for sandwich immunoassays, and (3) loss of CA215 binding by a given monoclonal antibody in the presence of excess of any other monoclonal antibodies (Lee et al., 2011). Furthermore, all of these monoclonal antibodies were shown to induce apoptosis to cancer cells upon incubation with $1 \mu \mathrm{g} / \mathrm{mL}$ of any of these monoclonal antibodies as clearly demonstrated in Figure 3C.

The reason for the existence of immunodominant carbohydrate-associated epitope(s) recognized by RP215 and other CA215-derived monoclonal antibodies in mice is currently unknown (Lee et al., 2011b). 


\subsection{Chimerization of RP215 and GHR106 monoclonal antibodies}

In order to proceed further with preclinical and clinical studies, efforts were made to generate human/mouse chimeric forms of RP215 and GHR106 monoclonal antibodies (Lee et al., 2009; Lee \& Ge, 2010a). Details of this genetic engineering process including the elucidation of primary structures of the Fab regions of these two monoclonal antibodies were performed through contract research services (Avantgen, San Diego). Generally speaking, both the murine and chimeric forms of RP215 and GHR106 were found to have almost identical binding affinity to their respective antigens, CA215 and GnRH receptor, on the cancer cells. Successful constructions of chimeric forms of these two monoclonal antibodies are essential to generate humanized forms as effective anti-cancer drugs for treatments of human cancers including that of the ovary.

\section{Experimental procedure}

\subsection{Chemicals}

All the chemicals were purchased from Sigma Chemicals Co (St Louis, MD) unless otherwise specified.

\subsection{Cell lines}

Human ovarian cancer cell lines, including OVCAR-3 and SKOV-3, as well as other cancer cell lines, including Raji and Jurkat were obtained from the American Type Culture Collection (ATCC), Rockville, MD, USA. All cell lines were cultured at $37^{\circ} \mathrm{C}$ in a humidified atmosphere consisting of $5 \% \mathrm{CO}_{2}$ and $95 \%$ air and maintained by subculturing cells twice a week according to supplier's instructions. OC-3-VGH ovarian cancer cell lines were established in 1986 by Dept. OBS/GYN, Veterans General Hospital, Taipei, Taiwan. This is the cell line of serus origin and has been used to serve as a model for the discovery and studies of RP215 in our laboratory (Lee et al., 1992). This cancer cell line was maintained in RPMI1640 containing 10\% fetal calf serum indefinitely.

\subsection{Western blot assays}

Western blot assay of cell extract from three ovarian cancer cell lines was performed according to the reported procedure (Lee et al., 1992; Liu et al., 1992). RP215 and GHR106 monoclonal antibodies were used as the respective probes to identify the molecular sites of CA215 as well as GnRH receptor in selected cancer cell extract. Briefly, sodium dodecyl sulfate polyacrylamide gel electrophoresis (SDS-PAGE) was performed with cancer cell extract in the presence of reducing agent ( $\beta$-mercaptoethanol). Indirect Western blot assays were carried out separately by using $10 \mu \mathrm{g} / \mathrm{mL}$ each of RP215 or GHR106 as the respective primary antibody probe for $1 \mathrm{~h}$ incubation at room temperature. Subsequently, alkaline phosphatase (ALP)labeled goat anti-mouse IgG was used as the secondary antibody for an additional $1 \mathrm{~h}$ incubation. This was followed by the color development with the substrate, pnitrophenylphosphate purchased from Bio-Rad Laboratories (Mississauga, ON, Canada). Appropriate positive and negative controls as well as the molecular weight standards (BioRad laboratories, Mississauga, ON, Canada) were included in the routine Western blot assay.

\subsection{Immunohistochemical studies}

The immunohistochemical staining experiments were performed by using the avidin/biotin complex (ABC) method from Vector Laboratories (Burlingame, CA). Methanol fixed OC-3- 
VGH, OVCAR-3 or SKOV-3 ovarian cancer cells were incubated with various primary antibodies (RP215 and GHR106) for $2 \mathrm{~h}$ at $37{ }^{\circ} \mathrm{C}$. Normal mouse IgG of the same concentration served as the parallel negative control. The incubation with labeled secondary antibodies as well as the colour staining was performed at room temperature for $1 \mathrm{~h}$ by following the protocols and instructions provided in the ABC Kits.

\subsection{TUNEL assay for assessment of cellular apoptosis}

TUNEL assay was performed to study the apoptotic effects of different monoclonal antibodies including RP215, ChRP215, GHR106 and ChGHR106 on cultured prostate cancer cells. In Situ Cell Death Detection Kit, POD (Roche, Canada) was employed for detection and quantitation of apoptosis at cellular levels. Briefly, OC-3-VGH, OVCAR-3 and SKOV-3 ovarian cancer cells were cultured in RPMI 1640 medium at $37^{\circ} \mathrm{C}$ in a $\mathrm{CO}_{2}$ $(5 \%)$ incubator for $24 \mathrm{~h}$ until all cancer cells became attached to the microwells. Selected antibodies of known concentrations were added separately and co-incubated for $48 \mathrm{~h}$. As the negative control, normal mouse IgG of the same concentration $(10 \mu \mathrm{g} / \mathrm{mL})$ was used for the same incubation period. At the end of the incubation, the attached cells were removed from the tissue culture wells. Apoptosis of treated cancer cells were determined quantitatively by TUNEL assay with the instruction provided by the supplier (Gorczyca et al.,1993).

\subsection{Complement-dependent cytotoxicity assay}

Complement-dependent cytotoxicity assay was performed according to the standard protocol described previously (Lee et al., 2011a). Briefly, 1 x $10^{5}$ cultured OC-3-VGH cells in $1 \mathrm{~mL}$ of appropriate culture medium (RPMI 1640 with $10 \%$ FCS) were plated in 24-well plates for $2 \mathrm{~h}$ before treatment. RP215, ChRP215, GHR106, and ChGHR106 were added separately to give a final concentration of $10 \mu \mathrm{g} / \mathrm{mL}$ and incubated for $15 \mathrm{~min}$ at room temperature, respectively. Three $\mu \mathrm{L}$ of freshly prepared rabbit baby complement (CL3441; Cedarlane labs, Burlington, NC, USA) was added to each well followed by incubation at $37^{\circ} \mathrm{C}$ for $2 \mathrm{~h}$. After incubation at room temperature, the cells were recovered by centrifugation. Trypan blue (0.4\%) (SV30084.01; Thermo Scientific, Waltham, MA, USA) was added and mixed gently. The percentages of cells stained with trypan blue were determined by cell counting under the regular microscope. Normal mouse IgG of the same concentration was used as the negative control. Incubation with the antibody or the complement alone served as the respective negative control for parallel comparisons in this experiment. Statistical analysis was performed to determine the significance of the assay by trypan blue method (Griffioen et al., 2009; Zhao et al., 2010).

\subsection{Total RNA extraction and cDNA synthesis}

Total RNA was extracted from OC-3-VGH, OVCAR-3, SKOV-3, Raji, and Jurkat cell lines (105-107 cells) by using QAIGEN RNeasy mini kit (Mississauga, ON, Canada) according to the manufacturer's manual. Total RNA integrity and quality were checked before the reverse transcription. RNase-free DNase set was performed to avoid genomic gene interference. Reverse transcription of total RNA $(0.5 \mu \mathrm{g}-5 \mu \mathrm{g} / 20 \mu \mathrm{L})$ to cDNA was performed by using oligo $(\mathrm{dT})_{15}$ primer and EasyScript first strand synthesis kit from Applied Biological Materials Inc. (ABM) (Richmond, BC, Canada) following the 
manufacturer's protocol. Reaction mixtures with RNA template but without reversetranscriptase were used as the negative controls for cDNA synthesis.

\subsection{Semi-quantitative analysis of mRNA expressions of selected genes by RT-PCR}

All primers required for PCR amplification were obtained from Integrated DNA Technologies (San Diego, CA) and listed as follows:

IgG: sense: 5'-ACGGCGTGGAGGTGCATAATG -3'; antisense: 5' -

CGGGAGGCGTGGTCTTGTAGTT-3'; T cell receptor a chain constant region: sense: 5'-

GTGCTAGACATGAGGTCTATGGAC-3' and antisense: 5'-

GGATTCGGAAGGGAATCACTGACAGG-3'; T cell receptor $\beta$ chain constant region: sense:

5'-TCTCGGCCACCTTCTGGC-3'; antisense: 5'-CATCAGCACGAGGGCACTGA-3'; CD3:

sense: 5'-CTCTCTGGCCTGGTACTGGC-3' and antisense: 5'-

GGCTGATAGACCTGGTCATTCCTCA-3'; CD4: sense: 5'

ACTAAAGGTCCATCCAAGCTGA-3' and antisense: 5'-

GCAGTCAATCCGAACACTAGCA-3'; CD8: sense: 5'-TTCGAGCCAAGCAGCGTCCT-3'

and antisense: 5' CGGCACGAAGTGGCTGAAGTA-3'; CD47: sense: 5'-

GAGTGATGCTGTCTCACACAC-3' and antisense: 5'-CTCATCCATACCACCGGATCT-3';

CD54: sense: 5'-CGGCACGAAGTGGCTGAAGTA-3' and antisense: 5'-

CGAGGTGTTCTCAAACAGCTCCAG-3'; CD58: sense: 5'-

AGAGCATTACAACAGCCATCG-3' and antisense: 5'-CGCTGCTTGGGATACAGGTT-3';

CD147: sense: 5'-CGAGGTGTTCTCAAACAGCTCCAG-3' and antisense: 5'-

CTTCCGGCGCTTCTCGTAGATG-3';

GnRH: sense: 5'-AACCTCTTCACCTTCTGCTGCCT-3' and antisense: 5'-

GATTTCTTCCCAGACCCTCTTACGAG-3'; GnRH receptor: sense: 5' -

TGACACGGGTCCTTCATCAG-3' and antisense: 5'-AAGTGGATCAAAGCATGGGTTT-

3'; NFkB: sense: 5'-CACTAAGCAGGAAGATGTGGTGGAG-3' and antisense: 5'

CATGGCAGGCTATTGCTCATCATGG-3;' P0: sense: 5' -TTGTGTTCACCAAGGAGG-3'

and antisense: 5'-GTAGCCAATCTGCAGACAG-3'; P1: sense: $5^{\prime}$ -

CAAGGTGCTCGGTCCTTC-3' and antisense: 5'-GAACATGTTATAAAAGAGG-3'; P2:

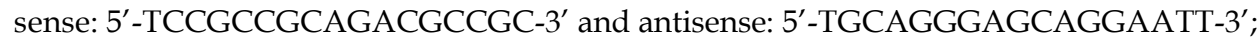

EGF: sense: $5^{\prime}$-AAGGAAATCCTCGATGAAGCCT-3' and antisense: $5^{\prime}$ -

TGTCTTTGTGTTCCCGGACATA -3'; c-fos: sense: 5'-GAGATTGCCAACCTGCTGAA-3' and antisense: 5'-AGACGAAGGAAGACGTGTAA-3'.

A house-keeping gene, glyceraldehyde-3-phosphate dehydrogenase was amplified and used as an internal control in the experiments. (Sense: 5'-GAAATCCCATCACCATCTTCC-3' and antisense: 5' - CCAGGGGTCTTACTCCTTGG-3').

PCR was performed by using $2 \times$ PCR MasterMix kit (ABM, Richmond, BC, Canada)

according to the manufacturer's protocols. After denaturing at $94^{\circ} \mathrm{C}$ for $4 \mathrm{~min}, 20-35$ cycles were performed under the following conditions: denaturing at $94^{\circ} \mathrm{C}$ for $40 \mathrm{~s}$; annealing at 58 ${ }^{\circ} \mathrm{C}$ for $60 \mathrm{~s}$ and extension at $72{ }^{\circ} \mathrm{C}$ for $60 \mathrm{~s}$. A final complete extension was then executed at $72{ }^{\circ} \mathrm{C}$ for $7 \mathrm{~min}$. At the end, the PCR product was checked by $1.5 \%$ agarose gel electrophoresis. The negative control from cDNA synthesis was further used in a PCR reaction and served as the negative control.

\subsection{Statistical analysis}

All experiments were performed in triplicate. All the results were presented as mean \pm S.D. Student $t$-test was performed to estimate the statistical significance. 


\section{Conclusion}

\subsection{General conclusion}

In this chapter, two monclonal antibodies, RP215 and GHR106, were identified, characterized and assessed to see if they are suitable for development of antibody-based anti-cancer drugs. The target antigens recognized by these two monoclonal antibodies, CA215 and GnRH receptor, were found to be expressed on the surface of cancer cells of many human tissue origins including that of the ovary (Lee et al., 2008). Initially, we have shown by immunohistochemical studies and Western blot assays (Lee et al., 2009) that these two monoclonal antibodies react specifically with antigens of three cancer cell lines, OC-3VGH, OVCAR-3 and SKOV-3. Immunohistochemical studies with tissue sections of 87 ovarian cancer specimens revealed that the positive staining rates with RP215 can be as high as $64.4 \%(56 / 87)$. These studies have become the basis for further preclinical studies to establish if these monoclonal antibodies are suitable as anti-cancer drugs for the treatment of ovarian cancers.

By in vitro apoptosis assay as well as complement-dependent cytotoxicity assay, we have been able to show that these two monoclonal antibodies or their chimeric forms could induce apoptosis to ovarian cancer cells and complement-dependent cytotoxicity reactions upon incubation with cultured cancer cells. Furthermore, in vivo nude mouse experiments with implanted OC-3-VGH ovarian cancer cells revealed significant dose-dependent inhibition of the growth of tumor cells by RP215 (Lee et al., 2009). By using MALDI-TOF MS for analysis of tryptic peptides derived from affinity-purified CA215, it can be shown that affinity-purified CA215 consist mainly of glycoproteins including immunoglobulin superfamily proteins and mucins. Therefore, some of the cancer cell-expressed CA215 with unique carbohydrate-associated epitope recognized by RP215 seems to be critical to the growth of cancer cells, in vitro or in vivo (Lee et al., 2011a).

Efforts have been made to elucidate the primary carbohydrate structures of RP215-specific epitope(s) in CA215 through extensive N-linked and O-linked glycoanalysis and glycosylation site mappings. It was generally concluded that oligosaccharides with terminal NeuGc with structures related to those in mucins might not be crucial in the epitope(s) recognition by RP215 (Lee \& Azadi, 2011).

The results of our studies have clearly demonstrated that GHR106, which reacts with the cancer cell-expressed GnRH receptor, can behave like a long acting GnRH analog in its biological actions except with a much longer half life (15-21 days) than the former (Lee \& Ge, 2010a). Similar to those of GnRH analogs, apoptosis of many human cancer cells can be induced for effective cancer treatments (Leung et al., 2003). In addition, complementdependent cytotoxicity and antibody-dependent cell-mediated cytotoxicity reactions could possibly be induced only with antibody-based anti-cancer drugs such as GHR106. We believe that the results presented in this study should provide a strong basis for these two monoclonal antibodies to be developed further in humans as anti-cancer drugs which might potentially target ovarian cancer as well as others in humans.

\subsection{Implications to the immunology of cancer cells}

It was generally postulated that certain tumor-associated antigens on the surface of cancer cells are overexpressed when compared with those of the normal cells (Rosenberg, 1995; Boon \& van der Bruggen, 1996; Topalian, 1994; Lee, 2009). Their specific antibodies can be induced or generated to inhibit the growth of cancer cells through mechanisms of cellular 
apoptosis, complement-dependent cytotoxicity and/or antibody-dependent cell-mediated cytotoxicity reactions (Oldham \& Dillman, 2008; Sanz et al., 2004). These have become the mechanistic basis of almost all the antibody-based anti-cancer drugs currently utilized for clinical treatments of human cancers (Finn, 2010; Wang \& Rosenberg, 1999). On the other hand, cancer cells can be neutralized through the mechanisms of T cell activations in vitro or in vivo (Wang \& Rosenberg, 1999) following appropriate processes (Zou, 2006). Based on this principle, the first anti-prostate cancer vaccine, Provenge (Sipuleucel-T) was developed and approved by the US-FDA for use clinically (Kantoff et al., 2010).

Similarly, in this study, we have explored the potential applications of RP215 and GHR106 monoclonal antibodies as antibody-based anti-cancer drugs. In the case of RP215, the molecular nature of CA215 and epitope-specific oligosaccharides were elucidated. Although our knowledge about the immunology of cancer cells has been advanced significantly, more questions arising from this study needs to be addressed here.

During the extensive molecular analysis of cancer cell-expressed CA215 with the unique carbohydrate-associated epitope recognized by RP215 monoclonal antibody, many glycoproteins involved in the normal immune system were identified and found to be highly expressed among many types of cancer cells, but rarely found in non-immune cells in humans. Among these are immunoglobulin superfamily proteins including all immunoglobulins, $\mathrm{T}$ cell receptors $(\alpha$ and $\beta$ ) and many cell adhesion CD molecules. The functional significance for the expression of these molecules in cancer cells remains to be explored (Lee et al., 2011a). First of all, the expression of immunoglobulins by cancer cells may be implicated with the existence of innate immunity in these cell types (Lee, 2009; Lee \& Ge, 2009). Secondly, the widespread expressions of T cell receptors in cancer cells may also have implications in immune activations of $\mathrm{T}$ cells as well as the immune tolerance by $\mathrm{T}$ cells on cancer cells (Lee et al., 2011a). Thirdly, the high expression of CDrelated cell adhesion molecules may facilitate the metastasis of cancer cells (Lee et al., 2011a). Therefore, more research work needs to be performed to resolve some of these puzzles.

We believe that for cancer cells to survive under the environment of the human immune system, a special protective mechanism should exist among cancer cells. Therefore, much more effort will be required to analyze and study the "immune system" of cancer cells, before any effective immuno-therapy of cancer cells can be achieved (Zou, 2006; Horna \& Sotomayor, 2006).

Another question which needs to be addressed is the preferential attachment of RP215specific carbohydrate-associated epitope(s) in cancer cell-expressed CA215. In the case of immunoglobulin superfamily glycoproteins, the common, but special glycosylations sites might be generated from the conserved and common domain structures of these types of molecules as reported previously (Lee \& Azadi, 2011). Mucin proteins, on the other hand, are known to consist of glycosylation sites which are favorable for the unique epitope attachments. However, it is equally difficult to explain the preferential absence of the RP215 recognition sites among the same proteins in normal cells. We believe that the unique RP215-specific epitope(s) is the result of aberrant expressions of certain glycosyltransferases (Yang et al., 1994; Brockhausen, 2000), which are common to all cancer cells. This question can be answered only when the carbohydrate moieties of the epitope(s) structures are completely elucidated in the future (Lee and Azadi, 2011). 
In this study, two potential antibody-based anti-cancer drugs were introduced and preclinical studies were performed. In view of the high and widespread expressions of the target antigens, namely, CA215 and GnRH receptor among ovarian cancer cells, we are optimistic about their potential in treating ovarian cancers following appropriate research, development and clinical trials in the near future.

\section{Acknowledgement}

This project was supported in parts by Vancouver Biotech Ltd, the NSERC and IRAP (\#743918) kindly.

Suzanne Potzold is a co-op student from Vancouver Biotech Ltd.

\section{Conflict of interest statement}

GL is co-founder of Vancouver Biotech Ltd.

\section{References}

Bast, R.C. Jr.; Klug, T.L.; Schaetzl, E.; Lavin, P.; Niloff, J.M.; Greber, T.F.; Zurawski, V.R. Jr. \& Knapp, R.C. (1984). Monitoring human ovarian carcinoma with a combination of CA 125, CA 19-9, and carcinoembryonic antigen. Am J Obstet Gynecol. 149(5):553-9.

Boon, T. \& van der Bruggen, P. (1996). Human tumor antigens recognized by T lymphocytes. J Exp Med. 183(3):725-9.

Brockhausen, I.(2000). O-linked chain glycosyltransferases. Methods Mol Biol. 125:273-93.

Chien, C.H.; Chen, C.H.; Lee, C.Y.; Chang, T.C.; Chen, R.J. \& Chow, S.N. (2004). Detection of gonadotropin-releasing hormone receptor and its mRNA in primary human epithelial ovarian cancers. Int J Gynecol Cancer. 14(3):451-8.

Choi, M.; Fuller, C.D.; Thomas, C. R. \& Wang, S. (2008). Conditional survival in ovarian cancer: results from the SEER dataset 1988-2001. Gynecol Oncol. 109(2): 203-9.

Dragunow, M. \& Faull, R. (1989). The use of c-fos as a metabolic marker in neuronal pathway tracing. J. Neuroscience Methods 29(3): 261-265.

Finn, O. (2008). Cancer Immunology. N Engl J Med. 358:2704-2715

Gorczyca, W.; Bigman, K.; Mittelman, A.; Ahmed, T.; Gong, J.; Melamed, M.R. \& Darzynkiewicz, Z. (1993). Induction of DNA strand breaks associated with apoptosis during treatment of leukemias. Leukemia. 7(5): 659-70.

Griffioen, M.; van Egmond, E.H.; Kester, M.G.; Willemze, R.; Falkenburg, J.H. \& Heemskerk, M. H. (2009). Retroviral transfer of human CD20 as a suicide gene for adoptive Tcell therapy. Haematologica. 94: 1316-1320.

Gründker, C.; Völker, P.; Schulz, K.D. \& Emons, G. (2000). Luteinizing hormone-releasing hormone agonist triptorelin and antagonist cetrorelix inhibit EGF-induced c-fos expression in human gynecological cancers. Gynecol Oncol. 78(2): 194-202.

Horna, P. \& Sotomayor, E.M. (2007). Cellular and molecular mechanisms of tumor-induced T-cell tolerance. Curr Cancer Drug Targets. 7(1):41-53. 
Huang, J.; Zhang, L.; Ma, T.; Zhang, P. \& Qiu, X. (2008). Expression of immunoglobulin gene with classical V-(D)-J rearrangement in mouse testis and epididymis. J Histochem Cytochem. 57(4): 339-49.

Jemal, A.; Murray, T.; Samuels, A.; Ghafoor, A.; Ward, E. \& Thun, M.J. (2003). Cancer statistics. Cancer J Clin. 53, 1, 5-26.

Kang, S.K.; Choi, K.C.; Yang, H.S. \& Leung, P.C. (2003) Potential role of gonadotrophinreleasing hormone (GnRH)-I and GnRH-II in the ovary and ovarian cancer. Endocr Relat Cancer. 10: 169-77.

Kantoff, P.W.; Higano, C.S.; Shore, N.D.; Berger, E.R.; Small, E.J.; Penson, D.F.; Redfern, C.H.; Ferrari, A.C.; Dreicer, R.; Sims, R.B.; Xu, Y.; Frohlich, M.W. \& Schellhammer, P.F. (2010). Sipuleucel-T immunotherapy for castration-resistant prostate cancer. $N$. Engl. J. Med. 363(5): 411-22.

Lee, G.; Chen, K.W.; Sheu, F.S.; Tsang, A.; Chao, K.C. \& Ng, H.T. (1992). Studies of a tumorassociated antigen, COX-1, recognized by a monoclonal antibody. Cancer Immunol Immunother. 35: 19-26.

Lee, G.; Wu, Q.; Li, C.H.; Ting, H.H. \& Chien, C.H. (2006). Recent studies of a new carbohydrate-associated pan cancer marker, CA215. J Clin Ligand Assay. 29: 47-51.

Lee, G.; Laflamme, E.; Chien, C.H. \& Ting, H.H. (2008). Molecular identity of a pan cancer marker, CA215. Cancer Biol Ther.7: 2007-2014.

Lee G. (2009). Cancer cell-expressed immunoglobulins: CA215 as a pan cancer marker and its diagnostic applications. Cancer Biomark. 5(3):137-42.

Lee, G. \& Ge, B. (2009). Cancer cell expressions of immunoglobulin heavy chains with unique carbohydrateassociated biomarker. Cancer Biomark.. 5: 177-188.

Lee, G.; Chu, R.A. \& Ting, H.H. (2009). Preclinical assessment of anti-cancer drugs by using RP215 monoclonal antibody. Cancer Biol Ther. 8: 161-162.

Lee, G. \& Ge, B. (2010a). Growth inhibition of tumor cells in vitro by using monoclonal antibodies against gonadotropin- releasing hormone receptor. Cancer Immunol Immunother. 59: 1011-9.

Lee, G. \& Ge, B. (2010b). Inhibition of in vitro tumor cell growth by RP215 monoclonal antibody and antibodies raised against its anti-idiotype antibodies. Cancer Immunol Immunother. 59(9): 1347-56.

Lee, G.; Cheung, A.P.; Ge, B.; Zhu, M.; Li, P.P.; Hsu, E. \& Huang, T-K. (2010a). MonoclonalAntiidiotype Antibodies against Carbohydrate-associate Epitope for Anti-Cancer Vaccine Development. J Vaccin Vaccinat. 1:106. doi:10.4172/21577560.1000106.

Lee, G.; Ge, B.; Huang, T-K.; Zheng, G.; Duan, J. \& Wang, I.H. (2010b). Positive identification of CA215 pan cancer biomarker from serum specimens of cancer patients. Cancer Biomark. 6(2): 111-7.

Lee G. \& Azadi. (2011). Peptide mapping and glycoanalysis of cancer cell-expressed glycoproteins, CA215 recognized by RP215 monoclonal antibody. The Journal of Carbohydrate Chemistry, in press.

Lee, G.; Zhu, M.; Ge, B. \& Potzold, S. (2011a). Widespread expression of immunoglobulin superfamily proteins in cancer cells. Cancer Immunol Immunother. in press. 
Lee, G.; Zhu, M.; Ge, B.; Cheung, A. P,; Chien,C.; Chow,S.; Ding. Y. \& Yao,H. (2011b). Carbohydrate-associated immunodominant epitope of CA215. Immunological Investigations, in press.

Leung, P.C.; Cheng, C.K. \& Zhu, X.M. (2003). Multi-factorial role of GnRH-I and GnRH-II in the human ovary. Mol Cell Endocrinol. 202(1-2): 145-53.

Li, Q. \& Verma, I.M. (2002). NF-kappaB regulation in the immune system. Nat. Rev. Immunol. 10: 725-734.

Liu, M.S.; Aebersold, R.; Fann, C.H. \& Lee, C.Y. (1992). Molecular and developmental studies of a sperm acrosome antigen recognized by HS-63 monoclonal antibody. Biol Reprod. 46: 937-948.

McGuire, W.P.; Hoskins, W.J.; Brady, M.F.; Kucera, P.R.; Partridge, E.E.; Look, K.Y.; ClarkePearson, D.L. \& Davidson, M. (1996). Cyclophosphamide and cisplatin compared with paclitaxel and cisplatin in patients with stage III and stage IV ovarian cancer. N Engl J Med. 334(1): 1-6.

Mørch, L.S.; Løkkegaard, E.; Andreasen, A.H.; Krüger-Kjaer, S. \& Lidegaard, O. (2009). Hormone therapy and ovarian cancer. JAMA 302(3): 298-305.

Oldham, R.K. \& Dillman, R.O. (2008). Monoclonal antibodies in cancer therapy: 25 years of progress. J Clin Oncol. 10;26(11):1774-7.

Qiu, X.; Zhu, X.; Zhang, L.; Mao, Y.; Zhang, J.; Hao, P.; Li, G.; Lv, P.; Li, X.; Sun, X.; Wu, L.; Zheng, J.; Deng, Y.; Hou, C.; Tang, P.; Zhang, S. \& Zhang, Y. (2003). Human epithelial cancers secrete immunoglobulin $G$ with unidentified specificity to promote growth and survival of tumor cells. Cancer Res. 63: 6488-6495.

Rosenberg, S.A.(1995). The development of new cancer therapies based on the molecular identification of cancer regression antigens.Cancer J Sci Am. 1(2):90-100.

Sanz L.; Blanco, B. \& Alvarez-Vallina, L. (2004).Antibodies and gene therapy: teaching old 'magic bullets' new tricks. Trends Immunol. 25(2):85-91.

Tan, A.; De La Peña, H. \& Seifalian, A.M. (2010). The application of exosomes as a nanoscale cancer vaccine. Int J Nanomedicine. 5:889-900.

Topalian, S.L. (1994). MHC class II restricted tumor antigens and the role of CD4+ T cells in cancer immunotherapy. Curr Opin Immunol.6(5):741-5.

Waldmann, T.A. (2003). Immunotherapy: past, present and future. Nat Med. 9(3): 269-77.

Wang, R.F. \& Rosenberg, S.A. (1999). Human tumor antigens for cancer vaccine development. Immunol Rev. 170:85-100.

Zhang, S.; Mao, Y.; Huang, J.; Ma, T.; Zhang, L.; Zhu, X.; Zheng, J.; Wu, L.; Yin, C.C. \& Qiu $X$. (2010). Immunoglobulin gene locus events in epithelial cells of lactating mouse mammary glands. Cell Mol Life Sci. 67(6): 985-94.

Yang, J.M.; Byrd, J.C.; Siddiki, B.B.; Chung, Y.S.; Okuno, M.; Sowa, M.; Kim, Y.S.; Matta, K.L. \& Brockhausen, I. (1994). Alterations of O-glycan biosynthesis in human colon cancer tissues. Glycobiology. 4(6):873-84.

Zhao, X.; Singh, S.; Pardoux, C.; Zhao, J.; Hsi, E.D.; Abo, A. \& Korver, W. (2010). Targeting C-type lectin-like molecule-1 for antibody-mediated immunotherapy in acute myeloid leukemia. Haematologica. 95: 71-78.

Zheng, J.; Huang, J.; Mao, Y.; Liu, S.; Sun, X.; Zhu, X.; Ma, T.; Zhang, L.; Ji, J.; Zhang, Y.; Yin, C.C. \& Qiu, X. (2009). Immunoglobulin gene transcripts have distinct VHDJH 
recombination characteristics in human epithelial cancer cells. J Biol Chem. 284(20): 13610-9.

Zou, W. (2006).Regulatory T cells, tumour immunity and immunotherapy. Nat Rev Immunol. 6(4):295-307. 


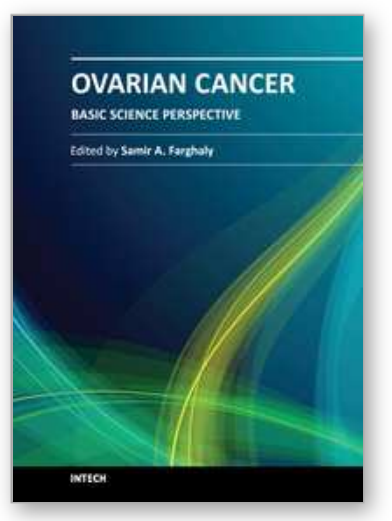

\author{
Ovarian Cancer - Basic Science Perspective \\ Edited by Dr. Samir Farghaly
}

ISBN 978-953-307-812-0

Hard cover, 406 pages

Publisher InTech

Published online 17, February, 2012

Published in print edition February, 2012

Worldwide, Ovarian carcinoma continues to be responsible for more deaths than all other gynecologic malignancies combined. International leaders in the field address the critical biologic and basic science issues relevant to the disease. The book details the molecular biological aspects of ovarian cancer. It provides molecular biology techniques of understanding this cancer. The techniques are designed to determine tumor genetics, expression, and protein function, and to elucidate the genetic mechanisms by which gene and immunotherapies may be perfected. It provides an analysis of current research into aspects of malignant transformation, growth control, and metastasis. A comprehensive spectrum of topics is covered providing up to date information on scientific discoveries and management considerations.

\title{
How to reference
}

In order to correctly reference this scholarly work, feel free to copy and paste the following:

Gregory Lee, Mingang Zhu and Bixia Ge (2012). Potential Monoclonal Antibody Therapy for the Treatment of Ovarian Cancer, Ovarian Cancer - Basic Science Perspective, Dr. Samir Farghaly (Ed.), ISBN: 978-953-307812-0, InTech, Available from: http://www.intechopen.com/books/ovarian-cancer-basic-scienceperspective/potential-monoclonal-antibody-therapy-for-the-treatment-of-ovarian-cancer

\section{INTECH}

open science | open minds

\section{InTech Europe}

University Campus STeP Ri

Slavka Krautzeka 83/A

51000 Rijeka, Croatia

Phone: +385 (51) 770447

Fax: +385 (51) 686166

www.intechopen.com

\section{InTech China}

Unit 405, Office Block, Hotel Equatorial Shanghai

No.65, Yan An Road (West), Shanghai, 200040, China

中国上海市延安西路65号上海国际贵都大饭店办公楼 405 单元

Phone: +86-21-62489820

Fax: +86-21-62489821 
(C) 2012 The Author(s). Licensee IntechOpen. This is an open access article distributed under the terms of the Creative Commons Attribution 3.0 License, which permits unrestricted use, distribution, and reproduction in any medium, provided the original work is properly cited. 